\title{
Water Regimes and Ecosystem in Lowland Paddy Field: A Case Study in Awlegama, Kurunegala, Sri Lanka
}

\author{
G.W.R.W.M.R.M.W.K.Kirinde ${ }^{*}$, N.D.K.Dayawansa ${ }^{1}$ and M.I.M. Mowjood $^{1}$ \\ Postgraduate Institute of Agriculture \\ University of Peradeniya \\ Sri Lanka
}

\begin{abstract}
Paddy fields are manmade ecosystems. These fields undergo three water regimes namely, aquatic, semi aquatic and terrestrial within a cultivation season. Accordingly, the ecosystem also changes. In addition, agronomic practices can affect biodiversity and the overall ecology. A study was conducted to assess the water regime and respective ecosystem so that ecosystem can be enhanced as an adaptation for climate variability in paddy cultivation. The study was conducted in a command area of Bayawa minor irrigation system located in Awlegama Agrarian service division in Kurunegala District, Sri Lanka. Six randomly selected locations in the field were used in the fauna survey at different growth stages in Yala season in 2015. A water management index (WMI) was developed to assess the water regime using physical factors of the field and social capacity of farmer. Results revealed that wet condition is expected in more than $69 \%$ of farmers since their WMI is more than 0.5. Water regime varied among head, middle and tail sections. Tail end of the command area has more reliability for water than the head and middle sections. The water fluctuation leads to higher biodiversity. The initial water regime and crop growth stages have provided more habitats for the both terrestrial and aquatic invertebrates. The abundance of aquatic invertebrates were significantly $(p=0.01)$ varied over the five growth stages anddragonflies' diversity was varied temporarily with respect to the species richness.Alternative wetting and drying have created more favorable habitats for aquatic fauna to increase the biodiversity of the fields. Increase of biodiversity promotes naturally enemies/predators for pests while aquatic fauna improve the nutrient availability in the fields. Therefore, water management in the fields could be used to enhance biodiversity in the rice field to achieve sustainable paddy cultivation.
\end{abstract}

Keywords: Biodiversity, ecosystem, invertebrates, paddy field, water regime

\section{INTRODUCTION}

An ecosystem is a functional unit composed of interacting and interdependent community of plants, animals and microorganisms, together with their non-living environment (Gopalet al., 2012). Agricultural systems where the natural resources are used to produce food, fiber, forest products, horticulture crops and their related services is a manmade ecosystem. Paddy is one of the major crops cultivated in large extents in Sri Lanka and plays a major role in ecosystem services such as flood protection, ground water recharge, biodiversity, soil conservation, pollution control and livelihood etc,. These ecosystem services are mainly

\footnotetext{
1 Department of Agricultural Engineering, Faculty of Agriculture, University of Peradeniya, Sri Lanka.

* Author for correspondence: 1986mayuri@gmail.com
} 
categorized under provisioning services, regulating services, supporting services and cultural services, etc. (Moldenet al., 2006).

Rice field ecosystem can be considered as an artificial wetland that is subjected to varying lengths of dry and wet phases (Bambaradeniya and Amerasinghe, 2003). This system is unique and can vary in biodiversity compared to other natural systems. Rice fields undergo three major ecological phases namely, aquatic, semi aquatic, and terrestrial dry, within a cultivation season. The water requirement for the crop and other field preparation vary with plant growth stages. Hence hydrological status of field is also varied with the different phenological stages namely vegetative, reproductive and ripening. Each phase of paddy plants would attract different types of fauna including terrestrial and aquatic vertebrates and invertebrates. The biodiversity in rice fields depends on quantitative status of water as well as its physico-chemical properties.

The duration of inundation and its regularity of water supply influence the temporal variations in water depth, water chemistry, soil fertility and the composition of aquatic biotic communities. Agronomic practices can regulate the overall ecology and biodiversity of the rice field ecosystem. Agronomic practices alter the chemical, physical, biological conditions in the rice eco systems, making them less favorable for certain organisms and temporarily more favorable for some others. The overall objective of the study is to investigate water regime and respective ecosystem so that ecosystem can be enhanced as an adaptation for climate variability in paddy cultivation.

\section{MATERIALS AND METHODS}

This study was conducted in 2015 in the command area of 44 ha in Bayawa minor irrigation system located in Awlegama Agrarian service division, Wariyapola Divisional Secretariat, Kurunegala District of Sri Lanka (Fig. 1).

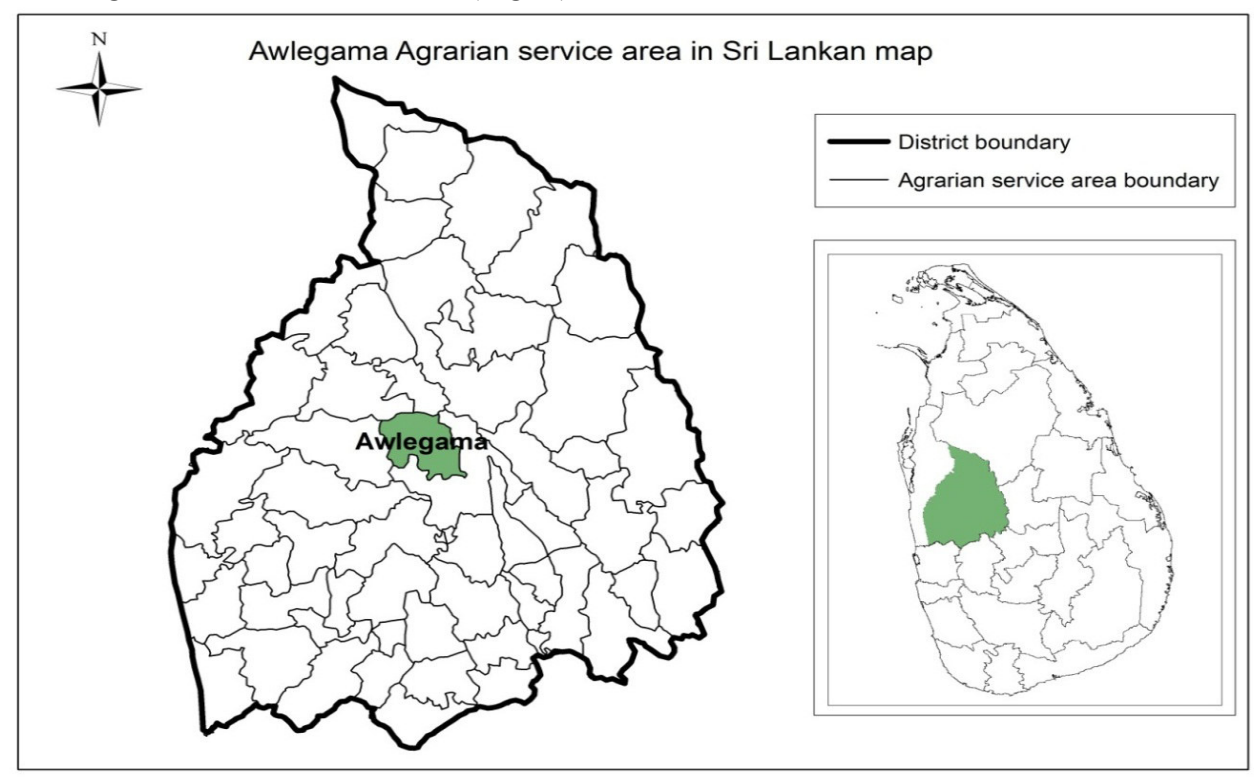

Fig. 1. Map of the Awlegama agrarian service division(1:60km) 


\section{Development of Water management Index (MWI)}

A questionnaire survey was conducted during the period of September to October in 2015, among randomly selected sixty farmers in the study area. The questionnaire was developed based on the factors that are directly or indirectly affect the water regime of rice fields. Farming factors (FF), temporal factors (TF), spatial factors (SF) socio economic factors (SEF) and institutional factors (IF) were considered. The parameters under each factor and the scores at different levels are shown in Table 1. High score was given to the wet conditions or with better water management while low score was given to the dry conditions or poor water management. For an example, presence of supplementary water source is given score 1 while the absence of supplementary water source is given 0 . Then Water Management Index (WMI) was developed using the Equation 1 with different weightage (Herathet al., 2011) for each factor considering their relative importance.

Table 1. Ranks given to the factors affecting water regime associated with paddy field ecosystem

\section{Farming Factors (FF)}

a. Soil conditions

\begin{tabular}{lc}
\hline Soil texture & Score \\
Sandy & 0 \\
Loamy & 1 \\
Clay & 2 \\
\hline
\end{tabular}

b. Location of field for water distribution

\begin{tabular}{lc}
\hline Water supplying and the water depth & Score \\
Plot to plot & 0 \\
Channel to plot & 1 \\
\hline & \\
c. Hardpan formation & Score \\
\hline Method of land preparation & 0 \\
2W Tractor & 1 \\
4 W tractor & \\
\hline
\end{tabular}

\section{Temporal factor (TF)}

b. Water source availability over the time

\begin{tabular}{lc}
\hline Supplementary sources & Score \\
Absence of supplementary water source & 0 \\
Presence of supplementary water source & 1 \\
\hline & \\
c. Climatic Factor & Score \\
\hline Threat from the natural impacts & 0 \\
Vulnerable to the drought & 1 \\
Vulnerable to the flood & \\
\hline
\end{tabular}




\section{Spatial factor (SF)}

a. Method of irrigation

Irrigation method

Aerobic method

Alternative wetting and drying method

Continuous shallow flooding

Score
0
1
2

b. Physical structure of the field

\begin{tabular}{lc}
\hline Structure of the field & Score \\
No bounds/damaged bunds & 0 \\
Clearing of channels, Well structured bund and leveled & 1 \\
field & \\
\hline & \\
c. Distance from the water source & Score \\
\hline Location of the field & 0 \\
Tail end & 1 \\
Middle & 2 \\
Head & \\
\hline
\end{tabular}

\section{Socio economic factors (SEF)}

a. Land Ownership

\begin{tabular}{lc}
\hline Land Ownership & Score \\
Lease / tenant & 0 \\
Own & 1 \\
\hline
\end{tabular}

b. Employment and enthusiasm

Involvement in farming

As a part time farming

As a full time farmer / farming as the main occupation

Score

0

1

c. Knowledge on farming

Farming experience and the knowledge on agronomic practices

No much experience on farming / engaged in farming for

Score

a shorter period

Well experienced on farming / farming engagement is for a

longer period

Institutional Factor (IF)

Irrigation schedule

\begin{tabular}{lc} 
Irrigational scheduling & Score \\
No proper schedule & 0 \\
Encompass a better schedule & 1 \\
\hline
\end{tabular}




\section{Assessment of water regime in rice fields using Water Level Observation (WLO) Well}

Water level fluctuations in paddy fields were measured during Yala 2015 to validate the assessed WMI. Perforated PVC pipes with $10 \mathrm{~cm}$ diameter and $40 \mathrm{~cm}$ length were used as water level observation wellas explained by Poh-kok (1988). Altogether 18 WLOwells were installed at the depth of $25 \mathrm{~cm}$ from the ground surface. The depth of water in each WLOwells was recorded daily for 60 days. Critical Tolerance Level (CTL) was defined as 0 $\mathrm{cm}$ as the ground surface for the study (Chandrasiri, 2016). The water regime of the field was assessed as reliability, resilience and vulnerability based on the CTL level (Poh-kok 1988). Then, the vulnerability was correlated with WMI.

The three indices of the water supply are defined as follows.

- Reliable : if the water level in the field does not fall below the CTL frequently, the water supply system considered to be reliable

- Resilience : if and when the water level goes below the CTL and recovers quickly without persisting below the CTL for an long period of time, the water supply system considered to be resilient

- Vulnerable : if and when the water level falls, and goes deeper and deeper below the CTL, it is considered to be vulnerable

\section{Assessment of Biodiversity of Rice Fields}

Aquatic fauna, dragonflies and birds were surveyed during Yala 2015 at the same locations, using standard sampling techniques. A total of 6 locations were identified as sampling points for dragonfly survey and birds' survey and 3 locations of command area were (Fig.2) used for aquatic fauna samplings. Further, command area was separated into 3 distinct localities as head, middle and tail section. Belts transect method (Chandana et al., 2012) was used for dragonfly sampling. The recorded dragonfly species were identified up to species level using a standard key (Bedjanic et al., 2007).

The bird species were surveyed using a standard fixed radius point count method (Subasinghe et al., 2014) with the radius set at $25 \mathrm{~m}$, during most active 6:00 to 9:00 $\mathrm{hr}$ period and bird composition was identified up to the species level using the Birds guide (Kotagama and Ratnavira, 2010). 


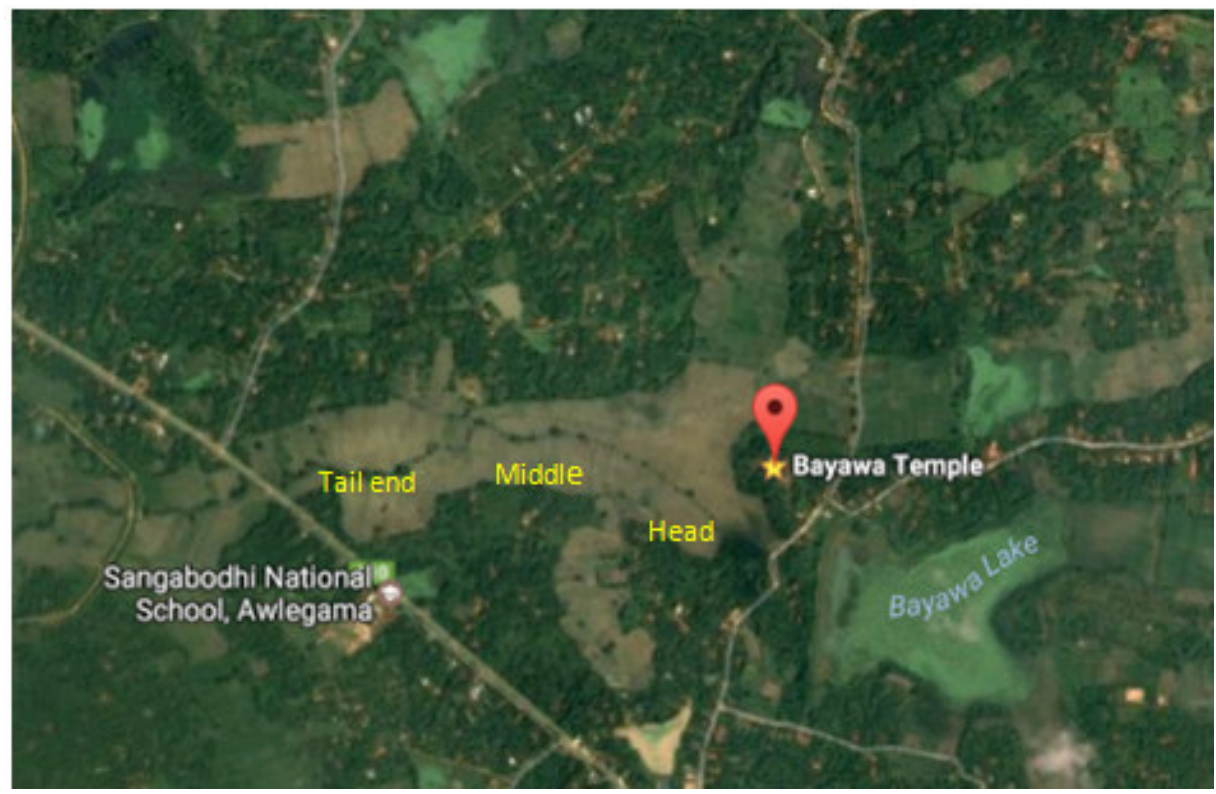

Fig. 2. Command area of BayawaTank (1:500)

The flood water was sampled using a $0.4 \mathrm{~L}$ dipper for studying aquatic fauna (Amerasinghe, 1995). Three replicates were collected from each site and in total 90 samples were collected in five visits. Then aquatic fauna was quantified onsite and each sample was brought to the laboratory and identified using the standard key. The samples of aquatic invertebrates including, adult invertebrates, larval forms and some of the protozoan were observed after sieving with mesh size $160 \mu \mathrm{m}$ filters and then they were identified, sorted and counted using lenses. Aquatic invertebrates such as snails were sampled using $0.3 \mathrm{~m}^{2}$ quadrates at the same sampling days.

\section{RESULTS AND DISCUSSION}

\section{Assessment of Water Regime using WMI}

Fig. 3 shows the WMI and number of farmer families in Awlegama. The WMI from 0 to 1 shows the trend from dry to wet water regime, respectively. Accordingly, $69 \%$ of farmer families have obtained higher (more than 0.5) WMI and shows the potential for wet conditions in their fields. Average WMI for head, middle and tail sections were 0.71, 0.55 and 0.52 , respectively. 


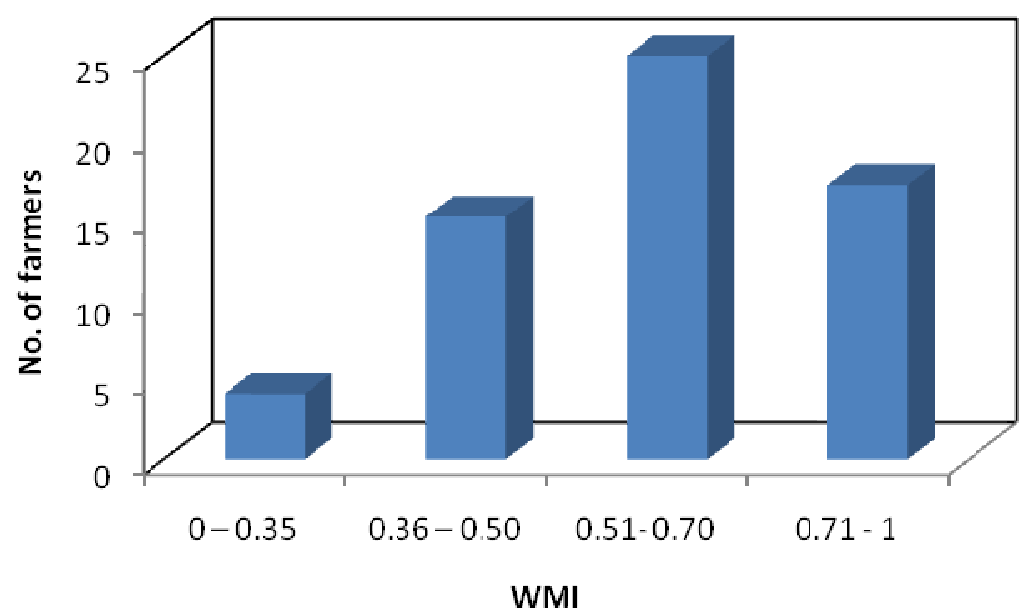

Fig. 3. WMI and number of farmers

\section{Assessment of Field Water Regime using WLO wells}

Reliability, resilience and vulnerability of the paddy fields are shown in Table 02 . Higher reliability found in the tail end means that the water level in the field does not fall below the CTL frequently. On other hand, the resilience was higher in head section since the water level recovers soon when it falls below the CTL. This proves that wetness of the field highly remained at head section than the other two sections. The vulnerability is higher in middle section and it describes the occurrence of dry condition of the field. These results show that comparatively wet conditions prevails at the head section of the field and dry conditions are at middle and tail end. This WLO well method confirms the results obtained in WMI (Table 02).

Table 2. Water regime in head, middle, tail sections from WLO wells

\begin{tabular}{cccc}
\hline Location & Reliability (\%) & Resilience (\%) & Vulnerability (\%) \\
\hline Head & 12 & 9 & 44 \\
Middle & 5 & 5 & 61 \\
Tail end & 33 & 7 & 50 \\
\hline
\end{tabular}

\section{Biodiversity Assessment of Dragonfly}

Species richness of dragonfly species in different growth stages and different locations are shown in Tables 3 and 4, respectively. Accordingly, species richness was higher at the sowing stage. Availability of food, predation and physical environment are very essential factors to determine the composition of dragonfly species in a particular area (Balzan, 2012). Use of chemical pesticides and fertilizers may result in the reduction in species and structural diversity of vegetation (Honkanen et al., 2011).Katayama et al. (2015) reported that intensive farming techniques such as applying chemicals have created loss of biodiversity in rice fields. Aquatic invertebrates including dragonfly species loss their larval stage habitat due to well drained fields. The species richness reduced with time within the season. 
Table 3. Species richness in different stages of paddy growth during Yala, 2015

\begin{tabular}{lc}
\hline Paddy growth stages & Species Richness \\
\hline Sowing stage (SS) & 11 \\
Seedling stage (2 WAS)* & 7 \\
Vegetative stage (4 WAS) & 8 \\
Reproductive stage (6 WAS) & 4 \\
Ripening stage (10 WAS) & 3 \\
\hline
\end{tabular}

*WAS-weeks after sowing

\section{Assessment of aquatic fauna}

The sampling at $0,2,4,6$ and 10 days after sowing represents sowing stage, seedling stage, vegetative stage, reproductive stages and ripening stage. Sowing and seedling stages are supplied with water continuously while other stages are with intermittent irrigation due to the irrigation schedule practiced. Gradual withdrawal of irrigation occurs at the ripening stage. Water depth of the field at the sowing stage was $2.5-5 \mathrm{~cm}$ while it was $7.5-10 \mathrm{~cm}$ at the reproductive stage.

As shown in Table 04, larvae and adult organisms were found within the paddy field eco system. Mosquito larvae were found as most abundant species. Mayfly and stonefly nymphs recorded at the later stages. These two species require highly oxygenated environment since they don't have gills and they use the diffused oxygen in water. Chironomid larvae (red blood worm) were abundant at vegetative stage where intermittent irrigation continues. Deoxygenated condition creates with no continuous irrigation in the field and mostly preferred by chironomid larvae. Most of the larval stages observed at the fields were predators and parasites and they feed on the other smaller invertebrates. The abundance of aquatic fauna significantly $(\mathrm{p}=0.01)$ varied over the five growth stages.

Adult stages found in the flood water were surface dwellers and submerged organisms. Plant feeders and pest such as snails and Pentatomid bugs of the rice fields were observed at the later stages. Back swimmers, water boatman and water mites were also found in all paddy growth stages. Snail species that belong to phylum molluscs have recorded in all paddy growth stages except vegetative stage. The highest snail population has been recorded during the reproductive growth stage. Snails prefer more wet paddies with poor drainage (Nakanishi et al., 2014). Exposure to severe predation at the initial stages would cause lower number of snails in the fields. The only vertebrate organisms recorded during the study period were tad poles that belong to the class Anura. Flood conditions and the rainy periods would lead them to reproduce and hatch in the ponding conditions.

\section{Assessment of Presence of Birds at Rice Fields}

Birds are predators of aquatic insects and its' presence is important to understand the aquatic biodiversity assessment. Fig.4 illustrates the percentage composition of variety of bird species during Yala, 2015. Wading birds are abundant during the initial cultivation phases than the later growth stages. Little egrets have recorded at a higher abundance than the other bird species and the abundance of those carnivore birds depend on the food source available in the fields. In general, birds visit rice fields in search of availability of food; fish, amphibians, small reptiles, crustaceans, molluses and insects etc., habitats and for 
reproduction. Considering all these factors, presence of birds was high during initial growth stages than the later stages.

a. Sowing stage

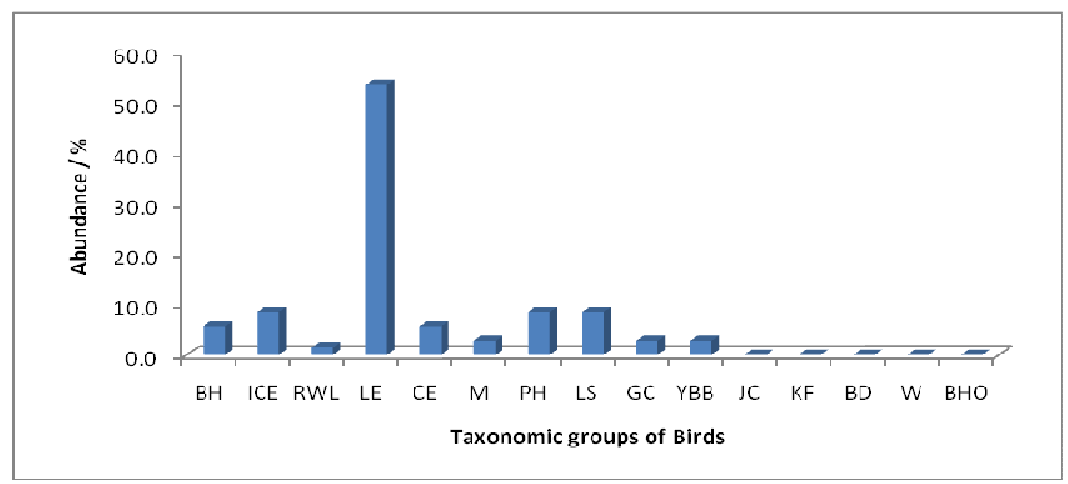

b. Two weeks after sowing stage

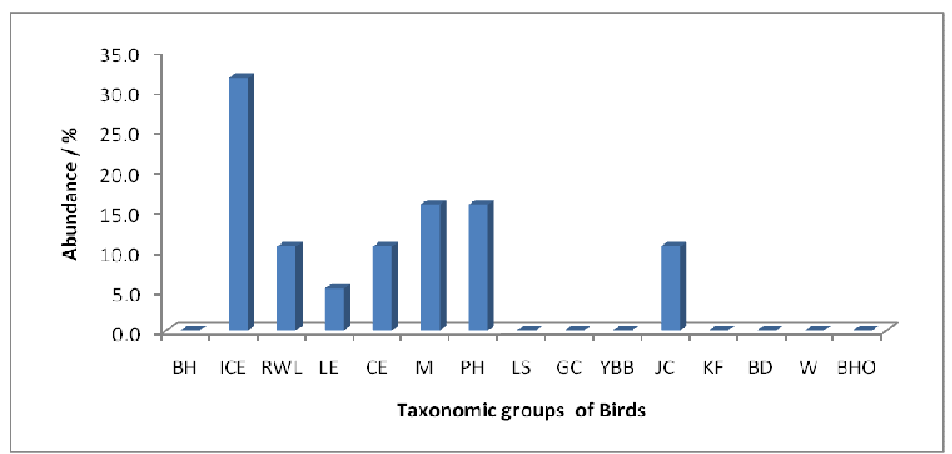

c. Four weeks after sowing stage

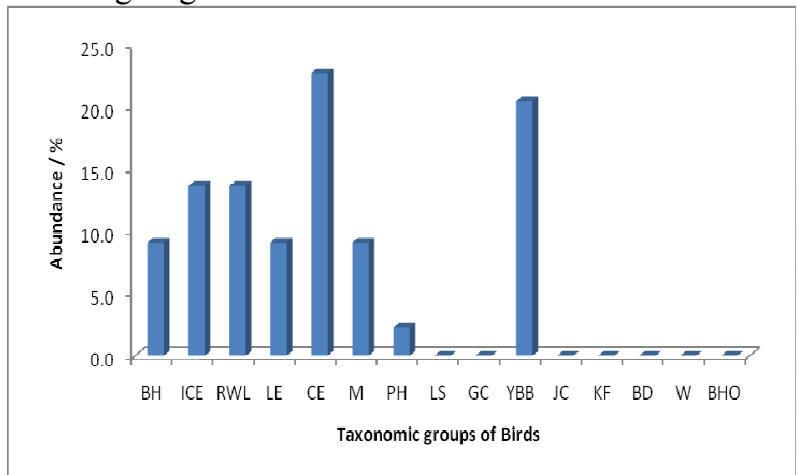


d. Six weeks after sowing

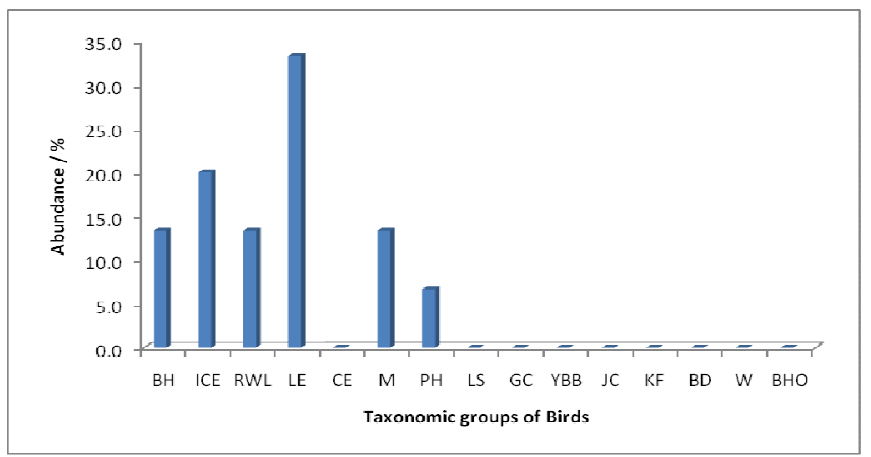

e. Ten weeks after sowing

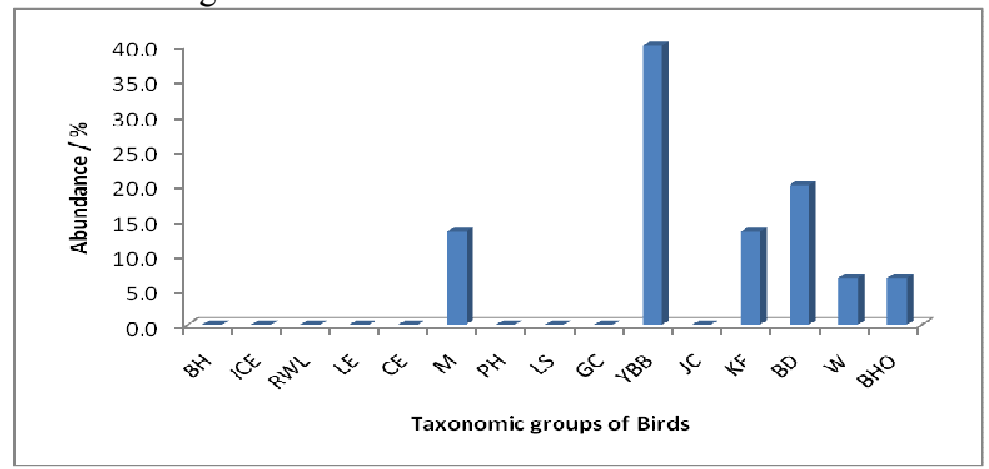

Fig. 4. Percentage composition of variety of bird species with growth stages

(BHI- black headed Ibis, ICE- Intermediate Cattle egret, RWL- Red wattled lapwing, LELittle egrets, CE-Cattle egrets, M-Mynah, PH- Pond heron, LS-Little swift, GC- Great caucal, YBB- Yellow billed babbler, JC-Jungle crow, KF- King fish, BD-Black drongo, WWoodpecker, BHO- Black hooded oriole)

Table 4. Abundance (\%) of different aquatic organisms at different growth stages in Yala season 2015

\begin{tabular}{lccccc}
\hline Organisms & SS & 2 WAS & 4 WAS & 6WAS & 10 WAS \\
& \multicolumn{7}{c}{ Larval stages } & & & \\
Mosquito larvae / pupae & 45 & 50 & 48 & 13 & 10 \\
$\begin{array}{l}\text { Midges / Biting and non biting } \\
\text { midges }\end{array}$ & 13 & 32.5 & 20 & 2 & 12 \\
Damselfly nymph & & & & & \\
Alderfly larvae & 2 & - & 1 & - & 3 \\
Stonefly nymph & - & - & 1 & 2 & 5 \\
Mayfly nymph & - & - & 8 & - & - \\
Dragonfly nymph & - & - & - & 8 & 3 \\
& - & 1 & - & - & 2 \\
\hline
\end{tabular}




\begin{tabular}{lccccc}
\hline Chironomid larvae & - & - & 1 & - & - \\
& \multicolumn{2}{c}{ Adult stages } & & & \\
Back swimmers & 24 & - & 2 & 6 & 2 \\
Water boatman & 3 & 1 & 10 & 5 & 3 \\
Pentatomid bug & - & - & - & 3 & - \\
Water spiders & 4 & - & - & - & - \\
Water mites & 2 & 4 & 6 & 17 & 34 \\
Daphnia & 2 & - & - & 2 & - \\
Hairy worms & - & 1 & 3 & - & 9 \\
Crabs & - & 0.5 & - & - & - \\
Ants & - & - & - & - & 3 \\
Snails & 5 & 2 & - & 42 & 12 \\
Tadpoles & - & 8 & - & - & - \\
\hline
\end{tabular}

\section{Biodiversity of Aquatic Fauna and WMI}

Variation of average diversity and WMI of sampling field in each section are shown in Table 5. Head location has obtained highest WMI value and the lowest average diversity value. Biodiversity of aquatic fauna is higher at fields in the middle section where the WMI is moderate. These fields are not allowed to have either dry or wet conditions continuously.

Table 5. Variation of average diversity of aquatic fauna and WMI

\begin{tabular}{lcc}
\hline Location of the field & WMI indices & Average Biodiversity \\
\hline Head & 0.68 & 0.77 \\
Middle & 0.61 & 1.15 \\
Tail & 0.57 & 1.05 \\
\hline
\end{tabular}

\section{Comparing of Biodiversity of Aquatic Fauna and Water Regime by WLO wells}

Table 6 , shows the variation of biodiversity and the reliability, resilience and vulnerability index values. High diversity value was obtained at the middle of the fields with lowest reliability. When the reliability was low, it has a tendency to fall the water level below CTL. Therefore, there is a higher level of water fluctuation which provides more niches for aquatic fauna by creating alternative dry and wet conditions. Diversity was the lowest when the resilience was higher. Recovering the water levels quickly means more or less constant water level is present in the flood water fields. This also further proves that water level fluctuation creates more diversity within the irrigated rice fields. This alternative drying and wetting in the fields create more habitat characteristics; variety of food sources, mating diversity and variety of predation to increase the species diversity in the field.

Table 6. Variation of biodiversity components and three indices values; reliability, resilience and vulnerability

\begin{tabular}{lcccc}
\hline $\begin{array}{c}\text { Location of } \\
\text { the field }\end{array}$ & $\begin{array}{c}\text { Biodiversity } \\
\text { Index }\end{array}$ & Reliability & \multicolumn{3}{c}{ WLO wells method } \\
Resilience & Vulnerability \\
\hline & & & & \\
Head & 0.77 & 12 & 9 & 44 \\
Middle & 1.15 & 5 & 5 & 61 \\
End & 1.05 & 33 & 7 & 50 \\
\hline
\end{tabular}




\section{CONCLUSIONS}

An index, WMI, was developed to assess the overall water regime of a paddy field considering the physical factors of the field and social capacity of the farmer. Wet condition is expected in fields of more than $69 \%$ of farmers since the WMI is more than 0.5 . Tail end of the command area has more reliability for water than the head and middle sections. These results were further confirmed by the WLO wells method.The abundance of aquatic fauna significantly varied over the five growth stages. Water regime also changed along with growth stages of the crops. Dragonflies' diversity was varied temporarily with respect to the species richness. The initial water regime and crop growth stages have provided more habitats for the terrestrial and aquatic invertebrates. Alternative wetting and drying have created more favorable habitats for aquatic fauna to increase the biodiversity of the fields. Increase of biodiversity promotes natural enemies/predators for pests while aquatic fauna improve the nutrients in the fields. Therefore, water management in the fields could be used to enhance biodiversity in the rice field to achieve sustainable paddy cultivation.

\section{ACKNOWLEDGEMENT}

This work was carried out with the aid of a grant from the International Development Research Center (IDRC), Ottawa, Canada. Their financial support is greatly appreciated.

\section{REFERENCES}

Amerasinghe, F.P., Indrajith, N.G. and Ariyasena.T.G. (1995).Physico Chemical Characteristics of Mosquito Breeding Habitats in an Irrigation Development Area in Sri Lanka,Cey. J. Sci. (Biol. Sci.) 24(2), 1995.

Balzan, M.V. (2012). Associations of Dragonflies (Odonata) to Habitat Variables within the Maltese Islands: A Spatio-Temporal Approach. Journal of Insect Science. Volume 12: 87.

Bambaradeniya, C.N.B. and Amarasinghe, F.P. (2003). Biodiversity Associated with the Rice Field Agro-Ecosystem in Asian Countries: A Brief Review. Working Paper 63.International Water Management Institute, Colombo, Sri Lanka.

Bedjanic., M., Conniff., K., and Wijeyeratne, G. (2007). Gehan's Photo Guide. A Photographic Guide to the Dragonflies of Sri Lanka.Jetwing Eco Holidays: Colombo.

Chandana E.P.S., Rajapaksha, A.C.D. and Samarasekara W.G.K.H. (2012). A survey of odonate assemblages associated with selected wetland localities in southern Sri Lanka. Asian Journal of Conservation Biology, 1(2), 67-73.

Chadrasiri, R.P.S.P. (2016). Evaluating and assessment of water management and its sustainability of paddy cultivation under variability rainfall in Bayawa, Kurunegala, Sri Lanka.Unpublished M.Phil thesis.Postgraduate Institute of Agriculture.University of Peradeniya.Peradeniya.

Gopal, B., Kotagama, H. and Gunawardena.E.R.N. (2012). Ecosystems and Integrated Water Resources Management: The Link and the need for Integration in Ecosystems \& Integrated 
Water Resources Management in South Asia, Ed. Gunawardena. E.R.N, Gopal, B., Kotagama, H, New Delhi, India, ISBN: 978-0-415-69305-9, PP. 1-12.

Herath, H.M.D.D., Mowjood, M.I.M. and Sivananthawerl, T. (2011). "Development of an index to assess accessibility to safe drinking water in dry zone of Sri Lanka: A case study in Medirigiriya DS division”, In: Symposium Proceeding of the Water Professionals' Day, pp. 71-83.

Honkanen, M., Sorjanen, A. and Monkkonen, M. (2011).Deconstructing responses of dragonfly species richness to area, nutrient, water plant diversity and forestry. Community Ecology-Oecologia, June 2011, 166(2), 457-467.

Katayama, N., Baba, Y.G., Kusumoto, Y., and Tanaka, K. (2015).A review of post-war changes in rice farming and biodiversity in Japan.Agricultural systems.132, 73-84.

Kotagama, S. and Ratnavira, G. (2010).An illustrated guide to the Birds of Sri Lanka.Field Ornithology Group of Sri Lanka. University of Colombo, Sri Lanka.1-351.

Molden, D., Fujimoto, N., Tharme, R. and Amerasinghe, P. (2006). Managing paddy fields for Ecosystem Services: Some insights from the comprehensive assessment of Water Management in Agriculture. 4th word water forum, joint session.INWEP and ICID. Mexico, pp. 3.

Nakanishi, K., Takakura, K., Kanai, R., Tawa, K., Murakami, D. and Sawada, H. (2014).Impacts of environmental factors in rice paddy fields on abundance of the mud snail (cipanagopaludinachinensislaeta).Journal of Molluscan studies.80(4),460-463.

Poh-kok, N. (1988). Irrigation Systems Performance Monitoring and Evaluation: Reliability, Resilience, and Vulnerability criteria for assessing the Impact of water shortage on rice yield. Review paper. International Water Management Institute, Colombo, Sri Lanka. 12 - 16.

Subasinghe, K., Sumanapala, A.P. and Weerawardhena, S.R. (2014).The impact of forest conversion on bird communities in the northern flank of the Knuckles mountain forest range, Sri Lanka.Journal of Asia Pacific Biodiversity. 367-373. 